\title{
ASAS KEKUATAN MENGIKAT DALAM KONTRAK WARALABA YANG MENGALAMI PERUBAHAN KAITANNYA DENGAN PERLINDUNGAN HUKUM TERHADAP FRANCHISEE BERDASARKAN PERATURAN PEMERINTAH NOMOR 42 TAHUN 2007 TENTANG WARALABA
}

\author{
Rilo Fisyahril Ramadhan \\ E-mail: f.rilo@yahoo.com \\ Mahasiswa Fakultas Hukum Universitas Sebelas Maret \\ Yudho Taruno Muryanto \\ E-mail: Yudho fhuns@yahoo.com \\ Dosen Fakultas Hukum Universitas Sebelas Maret
}

\begin{abstract}
This article aimed to find out the form of legal protection for franchisee in franchise contract that is amended based on Government Regulation Number 42 of 2007 about Franchise. This study was a normative law research that is prescriptive in nature using statute and conceptual approaches. This study employed primary, secondary, and tertiary law materials. The methods of collecting data used were library study and the law material collected was then analyzed using deductive method. This research finally found that the form of law protection for franchisee in franchise agreement as mentioned in Government Regulation Number 42 of 2007 about Franchise has not given consequence about the change of franchise contract and has not given law protection yet to franchisee because of the clauses about the termination of contract usually subjected to the franchisor's assessment. However, if one party makes another suffering from loss or does not perform the agreement in which it is the franchisee is thee weak or harmed party, the lost/harmed party can take legal attempt for getting compensation. It was consistent with the provision of Articles 1238 - 1243 of KUH Perdata (Civil Code).
\end{abstract}

Keywords: Legal Protection; Franchise agreement or contract; contract amendment

\begin{abstract}
Abstrak
Artikel ini bertujuan untuk mengetahui bentuk perlindungan hukum terhadap franchisee dalam kontrak waralaba yang mengalami perubahan berdasarkan Peraturan Pemerintah Nomor 42 tahun 2007 tentang Waralaba. Penulisan hukum ini merupakan penulisan hukum normatif yang bersifat preskriptif, bahan hukum yang telah terkumpul kemudian dianalisis dengan metode deduktif. Hasil penelitian menunjukan bahwa Peraturan Pemerintah Nomor 42 tahun 2007 tentang waralaba belum memberikan konsekuensi tentang perubahan kontrak waralaba, sehingga ketentuan ini belum memberikan perlindungan hukum kepada franchisee dalam perubahan kontrak waralaba, karena klausula tentang pemutusan perjanjian tunduk pada penilaian franchisor. Apabila salah satu pihak merugikan pihak lain atau wanprestasi yang mana franchisee lah pihak yang lemah dan dirugikan, maka pihak yang dirugikan dapat menuntut ganti rugi. Hal ini sesuai dengan ketentuan Pasal 1238 sampai dengan Pasal 1243 KUHPerdata.
\end{abstract}

Kata Kunci: Perlindungan Hukum; Perjanjian Waralaba; Perubahan Kontrak 


\section{A. Pendahuluan}

Seiring dengan perkembangan zaman dan begitu pesatnya sektor perekonomian yang semakin meningkat dan dinamis dengan penuh persaingan serta tidak mengenal batas-batas wilayah. Berbagai bisnis yang dijalankan dengan mudah untuk dilaksanakan, oleh karena itu bisnis di zaman sekarang memerlukan hukum untuk menaungi dan melindungi dengan tujuan untuk mewujudkan rasa keadilan sosial dan adanya kepastian hukum. Salah satunya bisnis waralaba atau yang biasa dikenal franchise.

Perjanjian dibutuhkan asas kekuatan mengikat terutama dalam perjanjian waralaba, karena asas kekuatan mengikat tersebut perlu dan mutlak dalam perjanjian waralaba. Asas kekuatan mengikat yaitu suatu perjanjian atau juga disebut asas Pacta Sun Servada terdapat pada Pasal 1338 ayat (1) dan ayat (2) KUHPerdata. Jika asas kekuatan mengikat sudah menjadi kontrak maka harus dilaksanakan dengan baik, penuh tanggung jawab dan itu tidak ada putusan sepihak, maka dalam pasal 1338 ayat (1) dan ayat (2) KUHPerdata jika terjadi perubahan kontrak maka harus dalam persetujuan para pihak. Namun bila ketentuan itu tidak ditaati dan dilaksanakan dengan itikad baik. Dikhawatirkan nanti franchisor dengan semenamena akan merubah klausul sesuai dengan kehendaknya sendiri, yang itu akan merugikan pihak franchisee. Dengan demikian perlindungan hukum bagi franchisee dalam perubahan kontrak waralaba sangat dibutuhkan.

Masalah perlindungan hukum bagi franchisee timbul sehubungan dengan adanya kekhawatiran bahwa franchisor akan memutuskan perjanjian atau menolak mempengaruhi perjanjian dan kemudian menolak memperbaharui perjanjian. Dalam hal ini timbul perbedaan pendapat mengenai apakah undang-undang yang mengatur pemutusan perjanjian untuk melindungi kepentingan franchisee memang diperlukan. Tentunya para pihak berharap, pelaksanaan perjanjian waralaba akan berjalan dengan baik.

Perjanjian waralaba merupakan perjanjian yang lahir di luar ketentuan KUHPerdata tetapi tetap tunduk pada KUHPerdata. Menurut Mancuso dan Donald Boroian (2006:185). Waralaba merupakan bisnis yang berbasis hubungan kontraktual, yaitu berdasarkan kontrak atau perjanjian antara pemberi waralaba dengan penerima waralaba, yang harus jelas bagi kedua belah pihak setelah mempelajari prospektus yang ditawarkan oleh pemberi waralaba. Prospektus tersebut berisi hal-hal yang wajib di informasikan oleh pemberi waralaba kepada calon penerima waralaba. Prospektus waralaba ini harus ditandatangani oleh calon penerima waralaba, pada halaman terakhir, sebagai tanda terima penawaran waralaba.

Berbagai analisis yang menyangkut materi perjanjian yaitu manajemen, royalti, serta penyelesaian sengketa akan memunculkan perhatian khusus bagi campur tangan negara atas franchising terutama aspek perlindungan hukum terhadap franchisee, persoalan yang muncul terhadap bisnis franchise yang ada selama ini tidak terlepas pula oleh aturan atau ketentuan yang secara tegas mengatur bisnis franchise yaitu Peraturan Pemerintah Nomor 42 tahun 2007 tentang waralaba. Pengaturan mengenai franchising melalui campur tangan negara bukan berarti berseberangan dengan prinsip-prinsip pasar bebas/perdagangan bebas (free market/Free trade), namun lebih tertuju pada penciptaan iklim bisnis franchise yang fair dan transparan, keseimbangan hak dan kewajiban para pihak merupakan dasar bagi pengaturan franchising yang telah begitu marak diIndonesia (Ery Agus. 2018:15). 
Berdasarkan uraian diatas, dalam artikel ini penulis hendak membahas mengenai bentuk perlindungan hukum terhadap franchisee dalam kontrak waralaba yang mengalami perubahan berdasarkan Peraturan Pemerintah Nomor 42 tahun 2007 tentang Waralaba.

\section{B. Metode Penelitian}

Metode penelitian yang penulis gunakan adalah penelitian hukum normatif atau biasa dikenal dengan hukum doktrinal, yaitu penelitian yang dilakukan dengan cara meneliti bahan pustaka atau data sekunder yang terdiri dari bahan hukum primer dan bahan hukum sekunder. Menurut Peter Mahmud Marzuki, semua penelitian yang berkaitan dengan legal research selalu normatif. Jika penelitian ini harus dinyatakan dalam bentuk tulisan cukup dikemukakan bahwa penelitian ini adalah penelitian hukum. Dengan adanya pernyataan demikian maka sudah jelas bahwa penelitian tersebut bersifat normatif. Hanya saja pendekatan dan bahanbahan hukum yang digunakan harus dikemukakan (Peter Mahmud Marzuki, 2014:55-56).

Penelitian ini bersifat preskriptif, yang memiliki tujuan untuk memberikan gambaran tentang bentuk perlindungan hukum terhadap franchisee dalam kontrak waralaba yang mengalami perubahan berdasakan Peraturan Pemerintah Nomor 42 tahun 2007 tentang Waralaba. Teknik pengumpulan bahan hukum menggunakan metode studi kepustakaan, kemudian dianalisis dengan menggunakan teknik analisis (pola berpikir) deduktif.

\section{Hasil Penelititan dan Pembahasan}

Berbagai analisis yang menyangkut materi perjanjian yaitu manajemen, royalti, serta penyelesaian sengketa akan memunculkan perhatian khusus bagi campur tangan negara atas franchising terutama aspek perlindungan hukum terhadap franchisee, agar waralaba dapat berkembang dengan pesat, maka persyaratan utama yang harus dimiliki satu teritori adalah kepastian hukum yang mengikat baik bagi Pemberi Waralaba (franchisor) maupun Penerima Waralaba (franchisee). Karenanya, kita dapat melihat bahwa di negara yang memiliki kepastian hukum yang jelas, waralaba berkembang pesat, misalnya di Amerika dan Jepang. Tonggak kepastian hukum akan format waralaba di Indonesia dimulai pada tanggal 18 Juni 1997, yaitu dengan dikeluarkannya Peraturan Pemerintah Nomor 16 Tahun 1997 tentang Waralaba. Peraturan Pemerintah Nomor 16 tahun 1997 tentang Waralaba ini telah dicabut dan diganti dengan Peraturan Pemerintah Nomor 42 Tahun 2007 tentang Waralaba.

Persoalan yang muncul terhadap bisnis franchise yang ada selama ini tidak terlepas pula oleh aturan atau ketentuan yang secara tegas mengatur bisnis franchise yaitu Peraturan Pemerintah Nomor 42 tahun 2007 tentang waralaba. Pengaturan mengenai franchising melalui campur tangan negara bukan berarti berseberangan dengan prinsip-prinsip pasar bebas/perdagangan bebas (free market/Free trade),"Food franchising business in Indonesia is growing up very fast. Factors that urge the growth are the specific characteristics of franchise inself, the rise of market demand, the availability of skilled labor, the high of return on investment and the internal factors such as the motivation, personality and the changing life style." (Warren Pengilley.1985:76).

Peraturan Pemerintah Nomor 42 tahun 2007 tentang Waralaba lebih tertuju pada penciptaan iklim bisnis franchise yang fair dan transparan, keseimbangan hak dan kewajiban para pihak merupakan dasar bagi pengaturan franchising yang telah begitu marak diIndonesia, 
disamping itu campur tangan oleh Negara. Pada prinsipnya, dilakukan sebagai upaya untuk mendinamisasikan perekonomian kelas menengah ke bawah sebagai mitra bisnis dengan perusahaan franchise, bukan dalam pengertian campur tangan yang pertentangan dengan asas kebebasan berkontrak, campur tangan yang dimaksud lebih ditujukan pada pembentukan kebijaksanaan bagi perjanjian franchise yang dibuat para pihak (M Muchtar Rivai, 2012: 11).

Dunia usaha untuk pembangunan perekonomi merupakan suatu pengolahan kekuatan ekonomi riil dimana dapat dilakukan melalui penanaman modal, penggunaan teknologi dan kemampuan berorganisasi atau manajemen. Sejak perekonomian dunia telah mengalami perubahan yang sangat dahsyat dan kini dunia termasuk Indonesia menyaksikan fase ekonomi global yang bergerak cepat dan telah membuka tabir lintas batas antar Negara. Dapat dikatakan pula bahwa dunia usaha adalah sebagai tumpuan utama yang dipergunakan sebagai pilar dan dilaksanakan dengan berbagai macam cara yang sekiranya dapat memupuk perkembangannya dengan lebih optimal dan berdaya guna (Syahrin Naihasy dalam Hukum Bisnis : 2005).

Oleh karena itu, Pemerintah merasa perlu untuk mengatur perjanjian waralaba terhadap perubahan kontrak ini dalam Peraturan Pemerintah Nomor 42 tahun 2007 tentang Waralaba dan Peraturan Menteri Perdagangan Nomor: 53/MDAG/ PER/8/2012 tentang Penyelenggaraan Waralaba, dalam rangka melindungi para penerima waralaba, atau setidaktidaknya berusaha agar perjanjian waralaba yang dibuat oleh para pihak tersebut memuat hak dan kewajiban yang setara.

Tidak selamanya usaha waralaba selalu mendatangkan keuntungan. Ada beberapa diantaranya menderita kerugian. Persoalan akan muncul apabila kerugian tersebut terjadi karena keadaan memaksa, atau kerugian tersebut terjadi padahal penerima waralaba telah menjalankan Standar Operasional Prosedur (SOP) dengan baik dan benar (Indira Hastuti. 2015:13).

Peraturan Pemerintah Nomor 42 tahun 2007 tentang waralaba pasal 16 sampai 18 hanya mengatur sanksi administratif.

Pasal 16 yang menyatakan:

1. Menteri, Gubernur, Bupati/Walikota sesuai kewenangannya masing-masing dapat mengenakan sanksi administratif bagi Pemberi Waralaba dan Penerima Waralaba yang melanggar ketentuan sebagaimana dimaksud dalam Pasal 8, Pasal 10, dan/atau Pasal 11.

2. Sanksi sebagaimana dimaksud pada ayat (1) dapat berupa:

a. Peringatan tertulis;

b. Denda; dan/atau

c. Pencabutan Surat Tanda Pendaftaran Waralaba.

Menurut East Asian Executive Report pada tahun 1983, waralaba digolongkan menjadi tiga macam, yaitu sebagai berikut :

1. Product Franchise, dalam hal ini franchisee hanya bertindak mendistribusikan produk dari parternya dengan pembatasan areal. Contohnya tempat pengisian bahan bakar minyak.

2. Processing/Manufacturing franchise, dalam hal ini franchisor hanya memegang peranan memberi know-how, dari suatu proses produksi. Contohnya minuman Coca-cola. 
3. Bussiness format or system franchise, di sini pemberi franchise sudah memiliki cara yang unik dalam menyajikan produk dalam satu paket kepada konsumen. Contohnya KFC, Pizza Hut, Mcdonalds dan lain-lain (Salim H.S, 2005:196).

Menurut Richard Burton Simatupang (1996: 41) bahwa jelasnya sebuah perjanjian semestinya harus menjelaskan secara detail dan komprehensif terhadap keinginan para pihak dan menghindari suatu pengertian atau perumusan yang ambivalen mengandung interprestasi ganda atau keraguan.

Seperti perjanjian pada umumnya, ada kemungkinan terjadinya wanprestasi dalam pelaksanaan Perjanjian Waralaba. Wanprestasi terjadi ketikan salah satu pihak tidak melaksanakan kewajiban sebagaimana tertera dalam Perjanjian Waralaba, yang menyebabkan salah satu pihak merasa dirugikan. Berdasarkan hal tersebut, maka secara khusus pihak yang dapat dirugikan dalam bisnis waralaba yaitu Pemberi Waralaba (franchisor) dan Penerima Waralaba (franchisee).

Bentuk perlindungan hukum terhadap franchisee dalam perjanjian waralaba dengan franchisor yang mengalami perubahan dalam Peraturan Pemerintah Nomor 42 tahun 2007 tentang waralaba tidak mengatur konsekuensi tentang perubahan kontrak waralaba, pada pasal 12 ayat 5 bahwa Surat Tanda Pendaftaran Waralaba berlaku untuk jangka waktu 5 (lima) tahun juga dalam pasal 16 ayat 1 hanya memberikan sanksi administratif bagi para pihak, tetapi tidak mengatur konsekuensi tentang perubahan kontrak waralaba, Hal ini dapat dilihat sebagai suatu upaya untuk mencegah franchisor memanfaatkan franchisee hanya sekadar untuk menguji pasar. Namun juga perlu dicermati klausula-klausula pasar. Dan perlu dicermati klausula-klausula tentang pemutusan perjanjian yang biasanya tunduk pada penilaian franchisor. Sehingga ketentuan ini belum memberikan perlindungan hukum kepada franchisee sebagai penerima waralaba, karena klausula-klausula tentang pemutusan perjanjian yang biasanya tunduk pada penilaian franchisor. Akan tetapi jika salah satu pihak merugikan pihak lain atau wanprestasi, yang mana franchisee lah pihak yang lemah dan dirugikan, maka pihak yang dirugikan bisa menuntut ganti rugi. Hal ini sesuai dengan ketentuan Pasal 1238 sampai dengan Pasal 1243 KUHPerdata.

Ganti rugi karena perbuatan melawan hukum adalah suatu bentuk ganti rugi yang dibebankan kepada orang menimbulkan kesalahan kepada pihak yang dirugikannya. Ganti rugi itu timbul karena adanya kesalahan, bukan karena adanya perjanjian. Ganti rugi karena wanprestasi adalah suatu bentuk ganti rugi yang dibebankan kepada debitor yang tidak memenuhi isi perjanjian yang telah dibuat antara kreditor dan debitor (Salim.H.S, 2003:181).

Mengenai syarat pembatalan perjanjian atau kontrak, dalam Pasal 1266 KUH Perdata menyebutkan bahwa perjanjian harus timbal balik, terdapat wanprestasi, dan pembatalannya harus dimintakan kepada hakim. Dalam hal penggantian biaya kerugian diatur dalam Pasal 1267 KUHPerdata yang menyebutkan pihak kreditor dapat menuntut debitor dengan cara pemenuhan perjanjian atau pembatalan disertai ganti rugi. Sebagai kesimpulan dapat ditetapkan, bahwa kreditor dapat memilih antara tuntutan-tuntutan sebagai berikut:

1. Pemenuhan perjanjian;

2. Pemenuhan perjanjian disertai ganti rugi;

3. Ganti rugi saja;

4. Pembatalan perjanjian;

5. Pembatalan disertai ganti rugi. (Subekti 1998:53). 
Dampak dari pemutusan perjanjian atau kontrak secara sepihak oleh franchisor pastinya sangat merugikan franchisee. Sehingga tidak menutup kemungkinan franchisee untuk menuntut ganti rugi atas kerugian yang dideritanya. Apabila franchisee menuntut ganti rugi, maka franchisor harus membayar kerugian tersebut. Demikian sebaliknya apabila wanprestasi atau kealpaan disebabkan oleh franchisee maka franchisor juga dapat menuntut ganti rugi. Sebelum menyatakan bahwa salah satu pihak wanprestasi baik dilakukan oleh franchisor maupun franchisee, maka para pihak menyelesaikan sengketa dengan cara musyawarah terlebih dulu dengan memberikan teguran atau somasi.

\section{Simpulan}

Bentuk perlindungan hukum terhadap franchisee pada perjanjian waralaba dengan franchisor yang mengalami perubahan dalam Peraturan Pemerintah Nomor 42 tahun 2007 tentang waralaba belum mengatur konsekuensi tentang perubahan kontrak waralaba, pada pasal 12 ayat 5 menjelaskan bahwa Surat Tanda Pendaftaran Waralaba berlaku untuk jangka waktu 5 (lima) tahun dan pasal 16 ayat 1 hanya memberikan sanksi administratif, tetapi tidak mengatur konsekuensi tentang perubahan kontrak waralaba. Sehingga ketentuan ini belum memberikan perlindungan hukum kepada franchisee sebagai penerima waralaba, karena klausula-klausula tentang pemutusan perjanjian yang biasanya tunduk pada penilaian franchisor. Akan tetapi jika salah satu pihak merugikan pihak lain atau wanprestasi yang mana franchisee lah pihak yang lemah dan dirugikan, maka pihak yang dirugikan bisa menuntut ganti rugi. Hal ini sesuai dengan ketentuan Pasal 1238 sampai dengan Pasal 1243 KUHPerdata.

\section{E. Saran}

Kepada Pemerintah dalam hal ini Menteri Perdagangan hendaknya hukum positif indonesia memiliki pengaturan undang-undang yang lebih spesifik untuk penerapan klausula baku dan perubahan kontrak dalam hal kontrak bisnis, untuk mencegah maupun melindungi pembisnis skala kecil dan menengah dari kerugian atau setidaknya kesetaraan kedudukan untuk hak dan kewajiban antara franchisor dan franchisee seimbang. Karena bisnis waralaba sudah bukan suatu yang baru lagi, sudah semestinya model usaha demikian memiliki pengaturan yang memadahi untuk menunjang perkembangan usaha dan juga memberikan proteksi bagi pihak-pihak dalam perjanjianya.

\section{F. Daftar Pustaka}

Ery Agus. 2018. “Aspek Keadilan Dalam Kontrak Bisnis di Indonesia”. Jurnal Law Reform. Volume 14. Nomor 1. Semarang: FH UNDIP.

Indira Hastuti. 2015. "Aspek Hukum Perjanjian Waralaba (Franchise)". E-Journal UNTAG. Volume 12. Nomor 1. Semarang: UNTAG Semarang.

M Muchtar Rivai. 2012. "Pengaturan Waralaba di Indonesia”. Jurnal Liquidity. Volume 1 Nomor 2. Jakarta: STIE Ahmad Dahlan Jakarta. 
Mancuso dan Donald Boroian. 2006. Peluang Sukses Bisnis Waralaba. Jogjakarta: Dolpin Book.

Peter Mahmud Marzuki. 2014. Penelitian Hukum. Jakarta: Prenda Media Group.

Richard Burton Simatumpang. 1996. Aspek Hukum Dalam Bisnis. Jakarta: Rineka Cipta.

Salim H.S. 2005. Hukum Kontrak Teori dan Teknik Penyusunan Kontrak. Jakarta: Sinar Grafika.

Subekti. 1985. Hukum Perjanjian. Jakarta: Intermasa.

Syahrin Naihasy. 2005. Hukum bisnis (Business Law). Yogyakarta: Media Pustaka.

Warren Pengilley. 1985. "International Franchising Arrangements and Problems in Their Negotiation". Northwestern Journal of International Law and business. Volume 7. Issue 2. Auckland: University of Auckland. 